doi.org/ 10.51891/rease.v8ir.3761

\title{
VIOLÊNCIA SEXUAL CONTRA AS MULHERES NO ESTADO DE SANTA CATARINA NO PERÍODO DE 2014 A 2020
}

\author{
SEXUAL VIOLENCE AGAINST WOMEN IN THE STATE OF SANTA CATARINA IN THE \\ PERIOD FROM 2014 TO 2020
}

\author{
Fernanda Pereira Labiak ${ }^{1}$ \\ Pedro Henrique de Moura Araújo ${ }^{2}$ \\ Pedro Cima Biage ${ }^{3}$
}

RESUMO: Neste estudo, o objetivo foi analisar a violência sexual contra as mulheres no estado de Santa Catarina no período 2014 a 2020. Utilizou-se dados primários oriundos de relatos de mulheres vítimas deste tipo violência e dados secundários advindos da Secretaria de Segurança Pública (SSP/SC), caracterizando uma pesquisa de natureza qualitativa e quantitativa. Os resultados da pesquisa qualitativa com 329 mulheres em Santa Catarina indicaram que elas não formalizaram denúncia às autoridades competentes mesmo tendo sido vítima de violência sexual, e que a faixa etária (4I,95\%) predominante na ocorrência do fato foi de o a 19 anos. Considerando a pesquisa quantitativa com os dados secundários da SSP/SC, identificou-se que das io.o86 notificações de violência sexual em Boletins de Ocorrência, a maioria das vítimas (53,82\%) estavam na faixa etária de o a 19 anos, e que o estupro foi a forma de violência sexual com mais casos $(76,44 \%)$ nos sete anos investigados. Estimase que as taxas de ocorrência reais da violência sexual no estado são mais altas que as estatísticas existentes, devido às subnotificações, seja por falta de denúncias por parte das vítimas, seja por questões institucionais, como as informações que se perdem no sistema por preenchimento errôneos, problemas técnicos ou desencorajamento da vítima na efetuação de denúncias por agentes públicos.

Palavras-chave: Violência sexual. Violência contra as mulheres. Violência de gênero. Estado de Santa Catarina.

ABSTRACT: In this study, the objective was to analyze sexual violence against women in the state of Santa Catarina from 2014 to 2020. Primary data from reports of women victims of this type of violence and secondary data from the Secretariat of Public Security (SSP/SC), featuring a qualitative and

\footnotetext{
${ }^{\mathrm{I}}$ Mestra em Educação pela Universidade Federal de Santa Catarina (UFSC). MBA em Gestão Estratégica de Pessoas pela Universidade Federal de Uberlândia (UFU). Psicóloga pela UFU. Docente no ensino superior. Pesquisadora na área de Estudos Interdisciplinares sobre Mulheres, Gênero e Feminismo. Conselheira no Conselho Estadual dos Direitos da Mulher (CEDIM/SC). Colaboradora na Comissão Especial de Psicologia, Justiça e Segurança Pública do Conselho Regional de Psicologia de Santa Catarina (CEPJUSP/CRP-Iz). ORCID - https://orcid.org/oooo-ooo2-8272-7IIX Lattes - http://lattes.cnpq.br/6972388317199472.

${ }^{2}$ Doutor em Engenharia de Produção pela Universidade Federal de Santa Catarina (UFSC). Mestre em Tecnologia da Informação e Gestão do Conhecimento pela Universidade Católica de Brasília. Matemático pelo Centro de Ensino Unificado de Brasília. Analista de sistemas no Instituto Nacional de Estudos e Pesquisas Educacionais Anísio Teixeira (Inep). ORCID - https://orcid.org/oooo-ooo3-657-8958

${ }^{3}$ Especialista em Direito Público pela Universidade Regional de Blumenau (FURBE). Bacharel em Direito pela Universidade Pitágoras de Uberlândia (UNIMINAS). Procurador Jurídico do Conselho Regional de Corretores de Imóveis de Santa Catarina - II ${ }^{\mathrm{a}}$ Região. ORCID - https://orcid.org/oooo-ooor-8753-596I
} 
quantitative research. The results of the qualitative research with 329 women in Santa Catarina indicated that they did not file a complaint with the competent authorities even though they were victims of sexual violence, and that the predominant age group $(4 \mathrm{I}, 95 \%)$ in which the fact occurred was from o to 19 years old. Considering the quantitative research with secondary data from the $\mathrm{SSP} / \mathrm{SC}$, it was identified that of the 10.086 notifications of sexual violence in police reports, $53,82 \%$ of the victims were in the age group from o to 19 years old, and that rape was the form of sexual violence with more cases $(76,44 \%)$ in the seven years investigated. It is estimated that the actual occurrence rates of sexual violence in the state are higher than the existing statistics, due to underreporting, either due to lack of complaints by the victims, or for institutional reasons, such as information that is lost in the system due to erroneous filing, technical problems or discouragement of the victim in filing complaints by public agents.

Keywords: Sexual violence. Violence against women. Gender violence. Santa Catarina state.

\section{INTRODUÇÃO}

A violência de gênero contra as mulheres consiste em qualquer ato que resulta, ou pode resultar, em dano físico, sexual ou psicológico, ou sofrimento, em seus diferentes níveis e formas, inclui agravos significativos na saúde física e mental das vítimas, com efeitos crônicos à médio e longo prazos, afetando a sua saúde e o bem-estar (Labiak; Sales; Araújo; Cruz; Luz, 202I). A violência sexual é uma forma de violência de gênero contra as mulheres, e, geralmente, é percebida na sociedade quando há extrapolação dos limites do sujeito no âmbito

sexual, provocando danos. $\mathrm{O}$ ato violento é dimensionado pela percepção do limite e da perturbação, o que varia de acordo com o meio em que o sujeito está inserido e a sua constituição enquanto sujeito. As especificidades culturais e as tradições são utilizadas, por vezes, para justificar determinadas práticas sociais danosas e violentas, perpetuando-as em vários níveis e formas. Nesse sentido, o limiar de identificação da violência perpassa pela individualidade e constituição biopsicossocialcultural do sujeito.

A violência sexual é definida pela Organização Mundial da Saúde [OMS] (2018, s/p) como "todo ato sexual, tentativa de consumar um ato sexual ou insinuações sexuais indesejadas; ou ações para comercializar ou usar de qualquer outro modo a sexualidade de uma pessoa por meio da coerção por outra pessoa," independentemente da relação constituída entre elas, em qualquer espaço, público ou privado. “A coerção pode ocorrer de diferentes formas e graus de força, assim como por intimidação psicológica, ameaça e extorsão, e nos casos em que a pessoa não tem condições de dar consentimento, como quando alcoolizada ou mentalmente 
incapaz" (ORGANIZAÇÃO PAN-AMERICANA DA SAÚDE/ORGANIZAÇÃO MUNDIAL DA SAÚDE [OPAS/OMS], s/d).

A Lei no 11.340 de 2006, popularmente conhecida como Lei Maria da Penha, compreende a violência sexual no contexto doméstico e familiar, no inciso III do artigo $7^{\mathcal{O}}$ como:

Qualquer conduta que a constranja a presenciar, a manter ou a participar de relação sexual não desejada, mediante intimidação, ameaça, coação ou uso da força; que a induza a comercializar ou a utilizar, de qualquer modo, a sua sexualidade, que a impeça de usar qualquer método contraceptivo ou que a force ao matrimônio, à gravidez, ao aborto ou à prostituição, mediante coação, chantagem, suborno ou manipulação; ou que limite ou anule o exercício de seus direitos sexuais e reprodutivos. (BRASIL, 2006, s/p).

A violência sexual ainda possui um caráter de invisibilidade na sociedade brasileira, é suprimida pelo conservadorismo característico da estrutura patriarcal que, nebulosamente, municiam os discursos para cerceamento dos diálogos sobre sexualidade e gênero, atribuindo o espectro de tabu. Nesse contexto, as searas da saúde e jurídica tem priorizado, ao longo dos anos, às consequências diretas e indiretas desse tipo de violência, ou seja, vigoram políticas voltadas às consequências da violência como denúncias, medidas punitivas para agressores/violadores e o atendimento especializado nos serviços de saúde para as vítimas, e negligenciado a prevenção voltada para a educação e a conscientização das pessoas, no intuito de evitar que ocorra tal violência.

Diante da fragilidade e escassez de políticas de enfrentamento à violência sexual, temse consolidado altos índices deste tipo de violência no Brasil. O estupro e o estupro de vulneráveis foram contabilizados, em 2019, com 61.347 notificações e, em 2020, com 53.453 notificações no país. No estado de Santa Catarina, a cada noo mil mulheres, 95,8 relataram ter sido vítimas de estupro em 2019; e 75,4 relataram ter sido vítimas deste crime em 2020. O que coloca Santa Catarina na sétima posição em 2019, e oitava posição em 2020, no que tange ao ranking dos estados brasileiros com maiores quantitativos de notificações de vítimas de estupros femininos (ANUÁRIO BRASILEIRO DE SEGURANÇA PÚBLICA, 2020/202I).

Os efeitos danosos da violência de gênero contra as mulheres não são apenas para as vítimas, a sociedade como um todo tem um ônus pelos custos de elas serem violentadas. Os altos custos das violências e crimes praticados contra as mulheres representam $2 \%$ do Produto Interno Bruto Global. Esse valor é estimado a partir das despesas com o atendimento das 
vítimas (médico, exames etc.), com a aplicação das leis (custos com medidas protetivas, casas de acolhimentos às vítimas, custos para manter os agressores custodiados quando são condenados etc.) e com as consequências das agressões para as mulheres inseridas no mercado de trabalho (afastamentos, aposentadorias precoces etc.) (ONU MULHERES, 2017).

As estimativas de custo total com a violência de gênero contra as mulheres não consideram outros problemas a ela relacionados, tais como gravidez indesejada e doenças sexualmente transmissíveis, abuso de álcool e drogas, tabagismo, adoecimento mental e psicológico, que são agravos comuns na esfera da violência sexual. Os danos dessa violência aliados aos seus custos demonstram a sua relevância econômica e social, bem como é um indicativo de se pesquisar as repercussões desse fenômeno, contribuindo para uma compreensão mais abrangente na sua real dimensão e impacto na economia do país. Com efeito, objetiva-se, neste estudo, analisar a violência sexual contra as mulheres no estado de Santa Catarina no período 2014 a 2020.

\section{MÉTODO}

Quanto ao delineamento metodológico deste estudo ${ }^{4}$, evidenciou duas etapas. $\mathrm{Na}$ primeira etapa foi utilizado dados secundários, referiu-se a um estudo de natureza quantitativa sobre as notificações de violência sexual contra as mulheres. Os dados foram oriundos de Boletins de Ocorrência (BOs/SC), no período de 2014 a 2020, disponibilizados pela Secretaria de Segurança Pública do Estado de Santa Catarina (SSP/SC, 202I) em fevereiro de 202I.

As violências e os crimes contra as mulheres elencadas no banco de dados foram categorizados, neste estudo, como física, psicológica, patrimonial, moral, sexual, homicídios (doloso e culposo), feminicídios, violências/crimes de múltiplas dimensões e outras. As categorias foram organizadas da seguinte forma: as violências física, psicológica, patrimonial, moral, sexual foram baseadas na Lei no Ir.340/2006; as violências/crimes de múltiplas dimensões foram criadas por não se encaixarem, à princípio, como física, psicológica, patrimonial, moral e sexual; os homicídios e os feminicídios foram caracterizados pela SSP/SC de acordo com o Código Penal brasileiro; e as outras ocorrências não foram

\footnotetext{
${ }^{4}$ Os dados apresentados neste estudo são um recorte de uma pesquisa maior dos autores sobre violência de gênero, na especificidade da violência contra as mulheres.
} 
identificadas, a princípio, como violências contra às mulheres, e envolveram, por exemplo, as notificações de acidentes de trânsito etc.

$\mathrm{Na}$ segunda etapa foi utilizado dados primários - relatos de mulheres que sofreram violência sexual no estado de Santa Catarina em algum momento da vida -, e abrange um estudo de natureza qualitativa. Para realização desta etapa, foi elaborado um questionário digital estruturado com ro questões, o qual foi compartilhado com a população investigada por meio das redes digitais de socialização e comunicação. O questionário foi respondido no período de or a 31 de março de 2021, e teve 329 respondentes do gênero feminino, residentes no estado de Santa Catarina.

Para tanto, abordou-se dados quantitativos das diferentes violências e crimes contra as mulheres notificados em BOs/SC, no período de 2014 a 2020, no intuito de visualizar em que posição a violência sexual se encontra quando comparada a outras formas de violências para, então, se proceder à análise das especificidades das violações sexuais. Por fim, analisou-se às violências sexuais sob a perspectiva das vítimas, de modo a tecer entendimentos e percepções, trazendo luz ao fenômeno.

\section{VIOLÊNCIA SEXUAL CONTRA AS MULHERES}

Os resultados da pesquisa realizada, bem como as discussões relacionadas foram organizadas de forma a analisar, em um primeiro momento, as notificações em BOs sobre as diferentes violências e crimes, aprofundando nas violências sexuais sofridas pelas mulheres no estado de Santa Catarina, no período de 2014 a 2020; e na sequência, os relatos de mulheres que sofreram violência sexual no estado de Santa Catarina em algum momento da vida.

\section{NOTIFICAÇÕES DE VIOLÊNCIA SEXUAL EM BOLETINS DE OCORRÊNCIA NO ESTADO DE SANTA CATARINA}

Os resultados encontrados, a partir do banco de dados da SSP/SC (202I), mostraram a persistência dos mais diferentes tipos de violências e de crimes contra às mulheres ao longo dos sete anos investigados. Na tabela I pode ser observado a frequência relativa das ocorrências registradas em BOs/SC, por ano, na especificidade das violências e crimes físicos, psicológicos, morais, patrimoniais, sexuais, homicídios dolosos ou culposos, feminicídios, de múltiplas dimensões e outros. 
Tabela I - Frequência relativa das notificações de violências e de crimes contra as mulheres apresentados por ano no estado de Santa Catarina

\begin{tabular}{|c|c|c|c|c|c|c|c|c|c|}
\hline \multirow{2}{*}{$\begin{array}{c}\text { Tipos de } \\
\text { Violências/Crimes }\end{array}$} & \multicolumn{7}{|c|}{ Ano } & \multirow[b]{2}{*}{ Total } & \multirow[b]{2}{*}{$\%$} \\
\hline & 2014 & 2015 & 2016 & 2017 & 2018 & 2019 & 2020 & & \\
\hline Patrimonial & $\begin{array}{c}38.85 \\
7\end{array}$ & $\begin{array}{c}39.29 \\
9\end{array}$ & $\begin{array}{c}43.70 \\
8\end{array}$ & 51.257 & $\begin{array}{c}43.77 \\
7\end{array}$ & 55.293 & $\begin{array}{c}54.54 \\
6\end{array}$ & 326.737 & 44,17 \\
\hline Moral & $\begin{array}{c}27.62 \\
0 \\
\end{array}$ & $\begin{array}{c}26.86 \\
3 \\
\end{array}$ & $\begin{array}{c}31.89 \\
8 \\
\end{array}$ & $\begin{array}{c}36.98 \\
0\end{array}$ & 35.953 & $\begin{array}{c}40.6 \mathrm{I} \\
6 \\
\end{array}$ & $\begin{array}{c}40.29 \\
7 \\
\end{array}$ & 240.227 & 32,48 \\
\hline Física & 20.101 & 18.853 & $\begin{array}{c}18.76 \\
\mathrm{o}\end{array}$ & $\begin{array}{c}20.46 \\
5\end{array}$ & I8.89I & 30.369 & 26.937 & $154 \cdot 376$ & 20,87 \\
\hline Sexual & 970 & 830 & 946 & I.I43 & I.394 & 2.462 & 2.345 & I0.090 & $\mathrm{I}, 36$ \\
\hline Psicológica & $\mathrm{o}$ & o & $\mathrm{o}$ & $\mathrm{o}$ & $\mathrm{o}$ & $\mathrm{o}$ & 5.473 & 5.473 & 0,74 \\
\hline $\begin{array}{l}\text { Homicídios } \\
\text { (doloso e culposo) }\end{array}$ & 80 & 80 & 92 & 78 & 68 & 132 & 99 & 629 & 0,09 \\
\hline Feminicídios & 27 & 28 & 35 & 33 & 35 & 65 & 66 & 289 & 0,04 \\
\hline Múltiplas dimensões & $\mathrm{o}$ & $\mathrm{o}$ & $\mathrm{o}$ & $\mathrm{o}$ & $\mathrm{o}$ & $\mathrm{o}$ & 733 & 733 & 0,10 \\
\hline $\begin{array}{l}\text { Outros tipos de } \\
\text { ocorrências }\end{array}$ & o & o & o & o & o & o & I.094 & I.094 & 0,15 \\
\hline Total & 87.655 & 85.953 & 95.439 & 109.956 & IOO.II8 & I28.937 & 131.590 & $\begin{array}{c}739.64 \\
8 \\
\end{array}$ & $\begin{array}{c}100,0 \\
0\end{array}$ \\
\hline
\end{tabular}

Fonte: elaborado pelos autores.

No somatório de 739.648 ocorrências relacionadas às mulheres no estado de Santa Catarina durante 2014 a 2020, a violência patrimonial (44,17\%) foi a que teve maior percentual, seguido das violências moral (32,48\%), física (20,87\%), sexual (1,36\%) e psicológica (o,74\%). De 2014 a 2019, a violência patrimonial aumentou 42,30\% e teve uma queda de $1,35 \%$ em 2020, a violência moral aumentou 47,05\% e teve uma queda de $0,78 \%$ em 2020, a violência física aumentou 5I,08\% e teve uma queda de II,30\% em 2020, a violência sexual aumentou 153,81\% e teve uma queda em de 4,75\% em 2020 e os homicídios de mulheres (doloso e culposo) aumentaram 65,00\% e tiveram uma queda de 25,00\% em 2020. Os feminicídios tiveram um aumento de $144,44 \%$ ao longo dos sete anos investigados, considerando as oscilações anuais. A violência psicológica ( 5.473 casos) e os crimes/violências de dimensões múltiplas (733 casos) tiveram registros apenas no ano de 2020. Salienta-se que na categoria crimes/violências de dimensões múltiplas foram elencados ocorrências de racismo, tráfico de pessoas etc.

$\mathrm{O}$ ano de 2020 foi atípico devido a pandemia da Covid-19, em que o primeiro caso de adoecimento no Brasil foi registrado em 26 de fevereiro deste ano. Para prevenir a 
disseminação do vírus Sars-CoV-2 foram adotadas, por autoridades sanitárias, medidas sanitárias de restrição social - isolamento social físico e quarentena -(MIGUEL; LABIAK, 2020a). Fator que pode ter influenciado para a queda das notificações de violências patrimonial, moral, física, sexual e de homicídios de mulheres e o início das notificações de violências psicológicas.

Por outro lado, quando se compara a violência sexual com os outros 4 tipos de violências descritas na Lei no II.340/2006, nota-se que esta violência é a quarta mais notificada nos $\mathrm{BOs} / \mathrm{SC}$, tendo apenas a violência psicológica na posição inferior, no que tange ao quantitativo de ocorrências (Tabelar). Dados que inquietam e fazem questionar: será que todas as meninas e as mulheres vítimas de violência sexual denunciam e fazem boletim de ocorrência? A resposta para este questionamento envolve mecanismos complexos relacionados à fatores externos instituídos socialmente (educação, legislações, sistema judiciário, segurança pública, entre outros) e internos que constituem o sujeito. Segundo a Pesquisa Nacional de Vitimização da Secretaria Nacional de Segurança Pública do Ministério da Justiça [SNSP/MJ] (2013), estima-se que cerca de 7,5\% das vítimas de violência sexual denunciam formalmente nos órgãos competentes.

Numa sociedade em que impera o modelo patriarcal, a cultura machista e os comportamentos sexistas, nem todas as meninas e mulheres que sofreram ou sofrem algum tipo de violência sexual se identificam como vítimas. Dialogar sobre a violência sexual é considerado tabu numa sociedade patriarcal conservadora. Logo, sem diálogo nas escolas, nos arranjos familiares, nos veículos de informação e comunicação, enfim, na sociedade em geral, o entendimento acerca das violações ao corpo e ao ser mulher, resta deveras prejudicado. Quanto menos uma mulher compreende os mecanismos que a oprime e a violenta, há maior probabilidade de ela se calar frente aquilo que a violenta, e, consequentemente, o sistema estrutural de violências é fortemente mantido. A falta de diálogo e esclarecimentos sobre o assunto é um dispositivo de poder que silencia as vítimas de violência sexual e colabora para manter o sistema estrutural de dominação do gênero masculino sobre o feminino.

Além do desconhecimento das formas de violações ao corpo e ao cerceamento do ser e estar na sociedade como mulher por meio de violências e crimes sexuais, meninas e mulheres sentem medo de serem desacreditadas socialmente e pelas instituições de justiça e segurança 
pública. As violências e os crimes sexuais são de difícil comprovação e, muitas vezes, acontecem de forma velada, em lugares longe dos olhares de testemunhas, e as vítimas são surpreendidas sem ter tempo de produzir uma prova contra o violador. Nesse caso, fica a palavra da vítima contra a do violador/agressor. E, numa sociedade patriarcal em que as mulheres são subjugadas e tratadas como segundo sexo (BEAUVOIR, 20I6), sua palavra é vista com desconfiança e, como consequência, pode passar da condição de vítima para acusada, por exemplo, pelo crime de calunia, quando as declarações dela são as únicas provas. Diante disso, é importante que as legislações, a segurança pública e o poder judiciário atuem de modo a combater o medo e o receio das vítimas de violência sexual a denunciarem os violadores/agressores, garantindo que, na prática, seja dado a devida importância à palavra da vítima, diante da forma que esses tipos de crimes acabam sendo praticados.

As leis que criminalizam as violências de gênero possibilitam gerar uma transformação cultural a longo prazo, uma vez que essas violências tendem a ser mais estudadas e discutidas, tornando-se mais divulgadas e, portanto, mais conhecidas. Porém Arruzza, Bhattacharya e Fraser (2019) pontuam que essas legislações não garantem que as mulheres abandonem o contexto da violência, e tampouco são eficientes para se prevenir o racismo e o sexismo institucionais. Agentes de segurança pública quando não preparados para atender mulheres vítimas de violência sexual podem levá-las à revitimização, ou seja, vitimá-las novamente com indagações que incutem a culpa nas mulheres, como se fossem responsáveis pelo comportamento criminoso dos violadores/agressores. Dito de outra forma, a análise do comportamento dos agressores/violadores é realizada deslocando-a para o comportamento das vítimas, questionando-as, constrangendo-as, intimidando-as e violentando-as psicologicamente e moralmente.

Posto que os fatores externos podem servir de barreiras para as vítimas de violências sexuais exporem o ocorrido e denunciarem formalmente aos órgãos competentes, tem-se os aspectos internos das próprias vítimas. Isto é, elas podem não se sentir preparadas psicologicamente e/ou emocionalmente para reviver a violência/crime por meio dos depoimentos nas diferentes instituições (segurança pública, Ministério Público, poder judiciário etc.), as quais vão confrontá-las e submetê-las à novas oitivas. As violências/crimes sexuais impactam de várias formas a vida das vítimas, ou seja, cada vítima as ressignificam de 
acordo com sua constituição biopsicossocialcultural. Algumas mulheres podem, por exemplo, desenvolver transtornos mentais como ansiedade, pânico, estresse pós-traumático, depressão, ideação suicida etc., além de sintomas psicossomáticos, desenvolver dificuldades para dormir, abuso de álcool e drogas (BRITO; EULÁLIO; DA SILVA JÚNIOR, 2020), outras mulheres podem "inconscientizar" a violência/crime, de modo que elas sabem o que aconteceu, mas não se recordam como aconteceu.

$\mathrm{E}$, ainda há aquelas vítimas que sentem vergonha de ter sido violentada sexualmente, isso, inclusive, é uma questão histórica, pois quanto mais perto a sexualidade feminina estiver da virtude, a violência sexual estará associada a desonra e maior será a rejeição e o sentimento de vergonha das mulheres (SEGATO, 2016). Por vezes, pode haver o sentimento de culpa por sofrer a violência sexual, como se elas fossem responsáveis pelo comportamento criminoso do violador. Numa sociedade que reforça o poder estrutural patriarcal existente, a responsabilidade da violência sexual é transferida para a vítima, levando-as a questionarem a si próprias, se podem ter tido algum comportamento que incentivou ou encorajou aquela prática, quando o fato em si representa a perda de controle do seu próprio corpo e o agenciamento do mesmo pela vontade do agressor (SEGATO, 2016; MUNIZ, 2019).

Quanto mais os agressores/violadores se apresentam como sujeitos bem-sucedidos socialmente e economicamente, a tendência é que as denúncias das meninas e das mulheres vítimas de violências sexuais sejam vistas com desconfiança e até mesmo sejam desacreditadas. Tais aspectos velados pairam em discursos sociais que atribuem caráter digno e idôneo irrefutável aos agressores do gênero masculino e duvidoso à vítima, a exemplo de: “ele tem família e é um profissional conceituado. Será que ela não está sendo oportunista?”. Segato (2016) pondera, nesse sentido, que, na maioria das vezes, os violadores/agressores estão inseridos na estrutura social existente, e praticam violências e crimes sexuais de forma oportunista, favorecido pela relação de poder estabelecida historicamente que concede inteligibilidade às suas ações. Diante disso, a intensidade do medo que as vítimas sentem dos agressores depõem o quão frágeis elas estão na relação de poder estabelecida entre os gêneros.

No que se refere à relação das violências e dos crimes sexuais com as mortes de mulheres, a análise dos dados agregados da SSP/SC (2021) não permite uma elucidação da questão, uma vez que não consta a motivação ou se houve algum tipo de violência antes dos 
homicídios e dos feminicídios. As notificações das mortes de mulheres por feminicídios e homicídios dolosos e culposos somam 918 casos no estado de Santa Catarina no período de 2014 a 2020 (tabela I). Observa-se que os anos de 2019 e 2020 tiveram os maiores números de notificações (2019 = 132 homicídios e 65 feminicídios $/ 2020=99$ homicídios e 66 feminicídios) . Estes dados acompanham a estatística em nível nacional, que teve uma alavancada nestes anos. No Brasil, em 2019, foram registrados 3.730 homicídios de mulheres, representando uma média de io mortes violentas por dia de mulheres. $O$ ano de 2019 terminou com 1.326 feminicídios (ANUÁRIO BRASILEIRO DE SEGURANÇA PÚBLICA, 20I9). Os homicídios dolosos de mulheres foram de 1.812 (primeiro semestre de 2019) para 1.848 (primeiro semestre de 2020), um crescimento de 2\%. Já as vítimas de feminicídio foram de 636 (primeiro semestre de 2019) para 649 (primeiro semestre de 2020), um aumento de 2\% (ANUÁRIO BRASILEIRO DE SEGURANÇA PÚBLICA, 2020).

A tabela 2 mostra os tipos e a quantidade de notificações de violência sexual registradas nos $\mathrm{BOs} / \mathrm{SC}$, no período de 2014 a 2020. Foram registrados 15 tipos de violência sexual em io.086 notificações ao longo dos anos investigados no estado de Santa Catarina.

Tabela 2 - Tipos e quantitativos de violência sexual registradas nos Boletins de Ocorrência no período de 2014 a 2020

\begin{tabular}{|c|c|c|c|c|c|c|c|c|}
\hline \multirow[b]{2}{*}{ Violência Sexual } & \multicolumn{7}{|c|}{ Ano } & \multirow{2}{*}{$\begin{array}{l}\text { Tota } \\
1\end{array}$} \\
\hline & 2014 & 2015 & 2016 & 2017 & 2018 & 2019 & 2020 & \\
\hline $\begin{array}{l}\text { I. Adquirir, possuir ou armazenar registro } \\
\text { contendo cenas de sexo explícito ou } \\
\text { pornográfica com criança ou adolescente }\end{array}$ & & & & & & & 3 & 3 \\
\hline $\begin{array}{l}\text { 2. Aliciar criança para se exibir de forma } \\
\text { pornográfica }\end{array}$ & & & & & & & 2 & 2 \\
\hline $\begin{array}{l}\text { 3. Aliciar, assediar criança com o fim de } \\
\text { praticar ato libidinoso com ela }\end{array}$ & & & & & & & 8 & 8 \\
\hline 4. Assédio sexual & & & & & & & 34 & 34 \\
\hline 5. Ato obsceno & & & & & & & 13 & 13 \\
\hline 6. Estupro & 969 & 827 & 94I & 1.133 & 1.221 & $\begin{array}{c}1.36 \\
9\end{array}$ & $\begin{array}{c}1.25 \\
0\end{array}$ & 7.710 \\
\hline 7. Estupro coletivo & & & & & & 15 & 17 & 32 \\
\hline 8. Estupro corretivo & & & & & & $\mathrm{I}$ & & $\mathrm{I}$ \\
\hline $\begin{array}{l}\text { 9. Facilitar acesso à criança de material } \\
\text { contendo cena de sexo explícito com o fim de } \\
\text { praticar ato libidinoso com ela }\end{array}$ & & & & & & & 2 & 2 \\
\hline
\end{tabular}




\begin{tabular}{|c|c|c|c|c|c|c|c|c|}
\hline $\begin{array}{l}\text { Io. Favorecimento da prostituição ou outra } \\
\text { forma de exploração sexual de menor ou de } \\
\text { vulnerável }\end{array}$ & & & & & & & I & I \\
\hline II. Importunação sexual & I & 3 & 5 & IO & I73 & $\begin{array}{c}\text { 1.07 } \\
7\end{array}$ & $\begin{array}{c}1.00 \\
5\end{array}$ & 2.274 \\
\hline $\begin{array}{l}\text { I2. Induzir alguém menor de I4 anos a } \\
\text { satisfazer a lascívia de outrem (Corrupção de } \\
\text { menores) }\end{array}$ & & & & & & & I & I \\
\hline 13. Mediação para servir a lascívia de outrem & & & & & & & I & I \\
\hline $\begin{array}{llll}\text { I4. Oferecer, divulgar registros } & \text { que } \\
\text { contenham cenas de sexo explícito } & \text { ou } \\
\text { pornográfica envolvendo } & \text { criança } & \text { ou } \\
\text { adolescente } & & & \\
\end{array}$ & & & & & & & 2 & 2 \\
\hline $\begin{array}{l}\text { 15. Produzir, dirigir, fotografar, filmar, } \\
\text { registrar cena de sexo explícito ou } \\
\text { pornográfica de criança ou adolescente }\end{array}$ & & & & & & & 2 & 2 \\
\hline Total & 970 & 830 & 946 & $\begin{array}{l} \\
\text { I.I43 } \\
\end{array}$ & $\begin{array}{c}\text { I. } 39 \\
4\end{array}$ & $\begin{array}{c}2.46 \\
2\end{array}$ & $\begin{array}{c}2.34 \\
\text { I }\end{array}$ & $\begin{array}{c}0.08 \\
6\end{array}$ \\
\hline
\end{tabular}

Fonte: elaborado pelos autores.

Pôde-se observar na tabela 2, que o estupro foi a violência sexual com maior número de notificações (7.710 casos) nos sete anos investigados, ocupando uma fatia de 76,44\% entre todos os tipos de violências sexuais registradas. Os anos de 2019 (I.369 casos) e 2020 (I.250 118 casos) tiveram mais notificações de estupro. Mesmo diante de oscilações nos quantitativos de notificações de estupro ao longo do período de 2014 a 2020, nota-se um crescimento de 29,00\%. A faixa etária das vítimas de estupro depreendeu 56,55\% de o a 19 anos, 17,65\% de 20 a 29 anos, Iо,62\% de 30 a 39 anos, 6,69\% de 40 a 49 anos, 3,29\% de 50 a 59 anos, 3,58\% $\geq 60$ anos e ı,62\% não foi informado. O estupro é um crime complexo em sentido amplo, conforme prevê o Código Penal brasileiro, em seu artigo 213, que o tipifica como “constranger alguém, mediante violência ou grave ameaça, a ter conjunção carnal ou a praticar ou permitir que com ele se pratique outro ato libidinoso" (BRASIL, 2009, s/p); e é considerado um crime hediondo (BRASIL, 1990).

As notificações de estupro coletivo em Santa Catarina aparecem nos anos de 2019 e 2020 com is e 17 casos, respectivamente, o que confere um aumento de 13,33\% de um ano para o outro. Dos 32 casos, 34,38\% das vítimas estavam na faixa etária de o a 19 anos, $18,75 \%$ estavam na faixa etária de 20 a 29 anos, 15,62\% estavam na faixa etária de 30 a 39 anos, e 31,25\% estavam na faixa etária de 40 a 49 anos. Em 2019 teve uma notificação de estupro corretivo no estado de 
Santa Catarina de uma vítima na faixa etária de o a 19 anos. No Código Penal brasileiro o estupro coletivo é caracterizado "mediante concurso de dois ou mais agentes", e o estupro corretivo busca "controlar o comportamento social ou sexual da vítima." (BRASIL, 2018, s/p).

A importunação sexual foi a segunda violência sexual com mais casos (2.274), contabilizando uma fatia de $22,55 \%$ entre todos os tipos de violências registradas ao longo de 2014 a 2020. Esta violência cresceu $100.400,00 \%$ durante os sete anos, partiu de um caso em 2014, chegando a I.005 casos em 2020. A faixa etária das vítimas desta violência compreendeu $44,99 \%$ de o a 19 anos, $27,70 \%$ de 20 a 29 anos, $13,59 \%$ de 30 a 39 anos, 7,21\% de 40 a 49 anos, $3,52 \%$ de 50 a 59 anos, $2,07 \% \geq 60$ anos e 0,92\% não foi informado. O Código Penal brasileiro no seu artigo 215-A tipifica importunação sexual como "praticar contra alguém e sem a sua anuência ato libidinoso com o objetivo de satisfazer a própria lascívia ou a de terceiro" (BRASIL, 2018, s/p).

No período investigado (2014-2020), o ano de 2020 teve II tipos de violências sexuais que não apareceram nos anos anteriores. Destes, o8 tipos de violências sexuais especificam no seu bojo que as vítimas foram criança(s) ou adolescente(s), e referem-se à: I) adquirir, possuir ou armazenar registro contendo cenas de sexo explícito ou pornográfica com criança ou adolescente; 2) aliciar criança para se exibir de forma pornográfica; 3) aliciar, assediar criança com o fim de praticar ato libidinoso com ela; 4) facilitar acesso à criança de material contendo cena de sexo explícito com o fim de praticar ato libidinoso com ela; 5) favorecimento da prostituição ou outra forma de exploração sexual de menor ou de vulnerável; 6) induzir alguém menor de I4 anos a satisfazer a lascívia de outrem (corrupção de menores); 7) oferecer, divulgar registros que contenham cenas de sexo explícito ou pornográfica envolvendo criança ou adolescente; e 8) produzir, dirigir, fotografar, filmar, registrar cena de sexo explícito ou pornográfica de criança ou adolescente. Estas violências sexuais contabilizaram 2I casos/notificações.

Sobre a idade das vítimas de violência sexual notificadas nos BOs/SC, 53,82\% estão na faixa etária de o a 19 anos;19,96\% na faixa etária de 20 a 29 anos; II,31\% na faixa etária de 30 a 39 anos; 6,85\% na faixa etária de 40 a 49; 3,34\% na faixa etária de 50 a 59; 3,20\% na faixa etária $\geq 60$ anos; e I,52\% não foi informado. É deveras preocupante o percentual de meninas menores de I9 anos que sofreram violências sexuais. Pondera-se, portanto, que ao ser violada, a sexualidade 
afeta gravemente as vítimas, principalmente quando se trata de crianças ou adolescentes por serem mais vulneráveis e não terem clareza e maturidade para identificar e enfrentar as situações de violência. Segundo o levantamento obtido pelo GLOBO com base nas notificações de violências sexuais de crianças e de adolescentes no Brasil, registradas pelo Ministério da Saúde, no período de 20II a 2018, o índice cresceu em 139,81\% (13.378 - 27.971 casos). As principais vítimas concentram-se no gênero feminino, quando comparado ao masculino, ou seja, de o a 9 anos, 76,4\% são meninas e 23,6\% são meninos, e de ro a I9 anos, 92,2\% são meninas e 7,8\% são meninos.

Em sua maioria, as diferentes violências sexuais notificadas nos BOs/SC no período investigado (2014-2020) foram praticadas por pessoas que não fazem parte do âmbito doméstico da vítima, contabilizando $73,81 \%$ em face a $26,19 \%$ que tiveram como violador/agressor alguém do âmbito doméstico da vítima. Dados que vão na contramão do levantamento feito pela Ferba/Giusti para a Childhood Brasil, a partir de 933 reportagens sobre o tema, veiculadas no online e nos impressos, entre I de janeiro e 3I de dezembro de 20I8, no qual apontam que familiares e pessoas próximas às vítimas são os principais agressores de violência sexual. Cerca de 37,00\% dos casos divulgados no Brasil, os agressores eram padrastos, pais, mães, avós e outros parentes. Apenas i6,00\% dos acusados de violência sexual contra crianças e adolescentes foram desconhecidos delas.

\section{RELATOS DE VÍTIMAS DE VIOLÊNCIA SEXUAL NO ESTADO DE SANTA CATARINA}

$\mathrm{Na}$ segunda etapa dos resultados, apresentou-se os dados coletados por meio de questionário estruturado no período de or a 31 de março de 2021, o qual teve 329 respondentes do gênero feminino, com idade entre 16 e 53 anos, residentes no estado de Santa Catarina. Constatou-se que Ioo\% das respondentes já foram vítimas de algum tipo de violência sexual ao longo da sua vida, sendo que a maioria (70,21\%) indicou ter sofrido mais de uma forma de violência sexual.

Sobre Santa Catarina ser o estado onde ocorreram as violências sexuais, 62,00\% confirmaram o ocorrido no estado; $36,48 \%$ apontaram ter sido vítima de violência sexual em Santa Catarina e em outro estado; e 1,52\% disseram que a violência sexual ocorreu em outro estado. Das violências sexuais ocorridas no estado de Santa Catarina, 65,74\% foram praticadas 
no período de 2014 a 2020 e 30,86\% ocorreram tanto neste período como posterior a ele, 3,40\% foram anteriores a este período.

Considera-se, diante disso, que $98,48 \%$ das participantes da pesquisa relataram ter sido vítimas de algum tipo de violência sexual no estado de Santa Catarina, e que 96,6o\% apontaram que a violência sexual aconteceu no período de 2014 a 2020. Estes dados são alarmantes por si só, mas quando associados ao fato de que $100 \%$ das participantes não formalizaram a denúncia às autoridades competentes por meio de $\mathrm{BO}$, revelam a censura social velada que intimida as vítimas de violência sexual para manterem sigilo das agressões sofridas e a impunidade dos agressores/violadores. Nesse sentido, cabe ponderar: como mudar essa realidade?

A violência de gênero contra as mulheres, na especificidade da violência sexual é um fenômeno multifacetado, e possui raízes que estão intimamente relacionadas com aspectos históricos, culturais, sociais, econômicos e políticos (LABIAK; NOVAIS; NUNES; SILVA, 2020). Por isso, é importante uma articulação dos poderes públicos (legislativo, executivo e judiciário) para atuarem em várias frentes sociopolíticas como a educação, a saúde, a assistência psicossocial, o sistema de justiça, a empregabilidade etc., a fim de promover, de modo adequado, o enfrentamento da violência gênero contra as mulheres. Contudo, em sua maioria, vivencia-se no contexto brasileiro a adoção de políticas públicas na educação não afinadas e alinhadas com o tempo histórico vivenciado no século XXI. Isto é, quando se proíbe e exclui a discussão sobre gênero dos currículos escolares, sob a alegação de se estar "incentivando a atividade sexual dos educandos", o que se pretende é manter a situação de privilégios daqueles que estão na posição de violentador/agressor, pois o silêncio das vítimas favorece os seus algozes a prosseguir com atos e comportamentos violentos.

A educação tem um papel importante no desenvolvimento da autonomia e da visão crítica dos educandos para formar uma sociedade mais justa, igualitária e humana (FREIRE, 2019). Portanto, quando se oportuniza aos educandos compreender os papéis de gênero na sociedade, possibilita a eles desenvolverem a cultura do respeito e modificarem a realidade das violências relacionadas ao gênero (LABIAK; MIGUEL, 2020; MIGUEL; LABIAK, 202I), porque eles tendem a se localizarem como parte do problema, tanto na ponta da ação, quanto na ponta da opressão. Isso é muito importante para anular o indiferentismo às violências de 
gênero contra as mulheres homogeneizadas nas práticas cotidianas (LABIAK; MIGUEL; NUNES, 2021).

Conforme os dados advindos do questionário, a violência sexual ocorreu quando as vítimas estavam nas faixas etárias de o a 9 anos (5,47\%), de ro a 19 anos $(36,48 \%)$, de 20 a 29 $\operatorname{anos}(31,32 \%)$, de 30 a $39 \operatorname{anos}(20,97 \%)$, de 40 a 49 anos $(5,46 \%)$ e de 50 a 59 anos (o,30\%). No que tange ao tipo de vínculo da vítima com quem praticou a violência sexual, identificou-se os seguintes sujeitos: pai (3,03\%), padrasto (3,34\%), irmão (8,51\%), tio (4,25\%), primo (10,63\%), avô (9,11\%), tio de uma amiga (2,27\%), pai de uma amiga (7,59\%), homem do ciclo de amizades (3,95\%), homem desconhecido (8,81\%), superior hierárquico no trabalho (7,29\%), colega de trabalho $(5,77 \%)$, marido $(3,64 \%)$, namorado $(8,20 \%)$, ex-marido $(3,64 \%)$, e vizinho $(9,97 \%)$.

Todas as 329 respondentes do questionário apontaram que não denunciaram formalmente a violência sexual sofrida, seja por meio de boletim de ocorrência ou para autoridades competentes, e dentre os motivos alegados, selecionou-se aleatoriamente: "Não senti confiança para denunciar."; "Fui ameaçada por quem me violentou."; "Não tinha como provar, era minha palavra contra a dele"; "Eu era uma criança e não sabia o que fazer. Meus pais e a escola não me orientaram para lidar com este tipo de situação.”; "Eu não tive coragem de denunciar."; "No consultório médico dele havia fotos familiares, passando a ideia de um profissional familiar e de confiança. Eu era uma jovem paciente, seria descredibilizada por todos. Foi isso que pensei."

Em relação a contar ou relatar o fato (a violência sexual) para alguém da confiança da vítima, o,6o\% das respondentes disseram ter contado imediatamente para uma pessoa de sua confiança após o fato ter ocorrido, 90,27\% disseram não ter contado para ninguém, e 9,13\% disseram ter contado para alguém depois muitos anos. Entre os motivos das respondentes não terem contado que foram vítimas de violência sexual, selecionou-se aleatoriamente os seguintes relatos: “Tive medo.”; “Tive medo de perder o emprego.”; “Tive medo de não acreditarem em mim.”; “Tive medo, pois adultos acreditam em adultos e não em crianças.”; “Tive vergonha."; "Eu não contei porque não tinha consciência da violência que tinha sofrido."; "eu não contei porque pensei que, se eu não tivesse naquele lugar e naquela hora, isso não teria acontecido comigo.”; “Não contei porque tive medo de julgamentos.”. 
Quando se soma os percentuais das faixas etárias de o a 9 anos e de ro a 19 anos, observa-se que, de o a 19 anos, atingiu o maior índice (41,95\%) entre os outros grupos etários. Esta faixa etária está associada ao período escolar (educação infantil, ensino fundamental e médio), portanto, a pergunta que surge é: será que, se não houvesse o cerceamento das discussões sobre gênero nos currículos escolares, na especificidade das violências de gênero como a violência sexual, as vítimas conseguiriam falar sobre o assunto com alguém da sua confiança e denunciar formalmente às autoridades competentes? Com base nos próprios relatos das vítimas, observa-se insegurança, medo e falta de esclarecimento de como proceder após a violação do seu próprio corpo, à exemplo: "Eu era uma criança e não sabia o que fazer. Meus pais e a escola não me orientaram para lidar com este tipo de situação.” (SIC). Ribeiro (20I6) destaca que, ao se estudar e dialogar com criticidade sobre a (des)igualdade de gênero, intenta-se empoderar as pessoas desprovidas de privilégios, dando voz a elas para que comecem a reivindicar seus direitos, o que culmina na perda dos privilégios de quem está no poder.

A violência sexual se caracteriza por atos impostos realizados por uma pessoa que usa seu poder para obter vantagens sexuais, com ou sem contato físico e/ou uso da força física (MACHADO et al, 2005). Pode ser realizada por adulto, adolescente, ou mesmo, criança, que pela idade ou desenvolvimento encontra-se num polo de poder, responsabilidade ou confiança em relação a quem está no polo da subjugação ou submissão. Observa-se nas respostas das vítimas de violência sexual, que grande parte dos autores da violência se encontram no âmbito doméstico, ou seja, 38,87\% dos agressores possuíam vínculo de parentesco com a vítima: pai, padrasto, irmão, tio, primo ou avô. Argumento importante para que as temáticas (des)igualdade de gênero, sexualidade, violência sexual, entre outras, sejam agregadas e discutidas na escola uma vez que os agressores/violentadores podem estar inseridos nas famílias e, consequentemente, o espaço de fala das crianças e das adolescentes resta deveras comprometido.

O âmbito doméstico pode ser inóspito também para as mulheres adultas, as respondentes apontaram que $15,48 \%$ dos agressores/violadores sexuais foram o marido, o namorado ou o ex-marido. Numa filosofia patriarcal em que as mulheres são entendidas como propriedades de pais e depois de cônjuges, elas são violentadas em diferentes níveis e formas 
como meio de fazê-las obedecer, submeter, corrigir, punir, servir e subalternizá-las (BUTLER, 20I6), e como tal, seus direitos, autonomia, integridade e vidas são desrespeitados, anulados e/ou assassinados. Por isso, é essencial combater a violência relacionada ao gênero, repensando os modelos relacionais que reforçam esta prática na cultura e na sociedade.

A violência de gênero contra as mulheres é um fenômeno que se dissemina nas relações entre as pessoas na sociedade. É caracterizada por uma relação desigual de poder, ou seja, uma relação hierárquica de desigualdade, com fins de dominação, exploração e opressão em que as mulheres são tratadas não como sujeito social, mas como coisas (LABIAK et al., 202I). O que confere a violência de gênero contra as mulheres o caráter de dominação de um lado e de coisificação do outro, e não somente a transgressão ou violação das leis ou normas por parte dos agressores/violadores. Dessa forma, os relatos das vítimas, neste estudo, ilustram esse dispositivo de poder do gênero masculino em relação ao feminino, ao identificar que a violência sexual foi praticada por diferentes sujeitos fora do âmbito doméstico das vítimas como tio e pai de uma amiga, homem do ciclo de amizades, homem desconhecido, superior hierárquico no trabalho, colega de trabalho e vizinho.

Os motivos elencados pelas respondentes para não terem contado que foi vítima de violência sexual para alguém de sua confiança, ou denunciado formalmente às autoridades competentes são diversos, mas é possível identificar um fio condutor entre as respostas elencadas, que são as especificidades da cultura e das tradições, as quais incutem nas vítimas o medo, a vergonha, a insegurança ou o desconhecimento do que fazer diante da violência perpetrada contra si. O Brasil ainda não conseguiu se desprender das amarras da cultura e das tradições patriarcais, as quais as pessoas do gênero feminino são ensinadas, desde cedo, a serem discretas, recatadas, silenciadas e submissas. Por estarem sob constantes ameaças de sofrer violência física, psicológica ou simbólica, o medo de se expressar são naturalizados assim como os comportamentos violentos direcionados às pessoas do gênero feminino.

\section{CONSIDERAÇÕES FINAIS}

Neste estudo, buscou-se analisar a violência sexual contra as mulheres no estado de Santa Catarina ocorridas no período 2014 a 2020. Para tanto, investigou dados oriundos da $\mathrm{SSP} / \mathrm{SC}$ e relatos de mulheres vítimas desta forma de violência. Verificou-se que, entre as 
cinco formas de violências tipificadas na Lei n⿳ำ II.340/o6, a violência sexual foi a quarta mais notificada em BOs/SC nos anos de 2014 a 2020, ficando acima apenas da violência psicológica. Contudo, ao relacionar os resultados da pesquisa advindos dos relatos de mulheres vítimas de violência sexual no estado, pondera-se que os quantitativos dessas notificações poderiam ser maiores, se 96,6\% das mulheres que disseram ter sido vítima deste tipo de violência entre 2014 e 2020 tivessem registrado formalmente o fato por meio de $\mathrm{BO}$. Isso demostra que a violência sexual fez e/ou faz parte da realidade de muitas mulheres catarinenses, mas possui um carácter de invisibilidade, repercutindo na ausência de denúncias. Diante disso, ressalta-se a importância de observar, quantificar, comparar este fenômeno para tirá-lo da invisibilidade, a fim de ser prevenido por meio de proposições efetivas do Estado e da sociedade como um todo.

A faixa etária com mais ocorrência de violência sexual foi de o a 19 anos, tanto no estudo com dados de BOs/SC (53,82\%), quanto no estudo referente aos relatos das vítimas (4I,95\%). Este resultado traz à tona a necessidade de uma reflexão ética e transformadora, que abarque uma compreensão crítica e complexa da sociedade, da história, dos costumes, das organizações sociais e políticas, dos direitos, das legislações, das políticas públicas existentes, das violações e das próprias noções de humanidade e dignidade, visando ampliar o olhar para a resolução da violência relacionada ao gênero, na especificidade da violência sexual.

Quando se relaciona os dados de $\mathrm{BOs} / \mathrm{SC}$ referentes à faixa etária com maior percentual de violência sexual (o-19 anos $=53,82 \%$ ) com os dados alusivos à maioria dos agressores não fazerem parte do âmbito doméstico das vítimas (73,81\%), cabe questionar e refletir que, geralmente, quem conduz as crianças e adolescentes (pessoas menores de idade) para registrar as ocorrências são seus responsáveis legais. Mas quando estes responsáveis legais são os violentadores sexuais, quem os acompanham na formalização da denúncia? Para quem as crianças vão pedir ajuda quando os algozes são aqueles que deveriam protegê-las? Refletir sobre isso, pode levar à indícios de subnotificação dos dados da SSP/SC por falta de denúncias. Uma vez que os dados de relatos das vítimas, na segunda parte do estudo, apontam que a maioria dos violadores/agressores foram pessoas do âmbito doméstico das vítimas. Estes dados mostram a necessidade de políticas públicas eficazes e eficientes que levem em consideração a necessidade da população feminina, que é viver livre de violências relacionadas 
ao gênero, independentemente da sua idade e marcadores sociais (classe, raça, orientação social, empregabilidade etc.).

Não é aceitável políticas públicas que silenciam as mulheres e que beneficiam os comportamentos abusivos e violadores dos agressores, assim como o cerceamento do diálogo sobre esse assunto nas escolas de Santa Catarina e de outros estados do Brasil. É primordial proteger aqueles que estão em situação de vulnerabilidade e não mascarar as vulnerabilidades e as violências, perpetuando-as. As políticas públicas devem ser articuladas com a realidade da população e não ser decisões manipuladas politicamente para atender os interesses daqueles que violam direitos e vidas.

No âmbito da violência sexual, os estupros foram os mais notificados nos BOs/SC $(76,44 \%)$. Pondera-se que a sociedade necessita de conhecimento mais amplo a respeito da violência de gênero contra as mulheres, na especificidade da violência sexual, não apenas focado nas informações acerca das formas de violência sexuais, ou como combatê-las dentro da seara jurídica e das medidas punitivas atualmente aplicadas, e que se apresentam insuficientes - não por serem "brandas" demais, mas por apenas reprimirem os agressores após o ato de violência, ignorando tanto a existência de uma vítima, quanto a existência de uma estrutura patriarcal envolvida, e que culmina em violência de gênero contra as mulheres. Ignorar tal fato é relativizar o papel da sociedade na perpetuação da violência de gênero contra as mulheres.

Em suma, acredita-se que as reflexões propostas neste estudo podem ser úteis para diferentes áreas do conhecimento, permitindo que os saberes transitem de modo interdisciplinar e ampliem os espaços de diálogo sobre a (des)igualdade de gênero e as violências/crimes praticados devido ao gênero, contribuindo para conscientizar sujeitos no intuito de prevenir tais violências/crimes, e incentivar o protagonismo das meninas e das mulheres na busca pelo pleno usufruto de seus direitos. Isso porque mesmo vivendo em situação de violência, as mulheres continuam sendo capazes de resistir e de agir, fato que justifica o investimento em políticas públicas que visem o seu empoderamento e a sua emancipação. 


\section{REFERÊNCIAS}

ANUÁRIO BRASILEIRO DE SEGURANÇA PÚBLICA. Anuário Brasileiro de Segurança Pública de 2020. Fórum Brasileiro de Segurança Pública, 2020. Disponível em: https://forumseguranca.org.br/wp-content/ro/anuario-I4-2020-vi interativo.pdf. Acesso em: 04 Jul. 2021.

ANUÁRIO BRASILEIRO DE SEGURANÇA PÚBLICA. Anuário Brasileiro de Segurança Pública de 2019. Fórum Brasileiro de Segurança Pública, 2019. Disponível em: https://www.forumseguranca.org.br/wp-content/uploads/2019/o9/Anuario-2019- FINALv3.pdf. Acesso em: 04 Jul. 2021.

ARRUZZA, C.; BHATTACHAYA, T.; FRASER, N. Feminismo para os 99\%: um manifesto. São Paulo: Boitempo, 2019.

BEAUVOIR, S. de. O Segundo Sexo: Fatos e mitos. Vol. 2, Rio de Janeiro: Nova Fronteira, 2016.

BRASIL. Lei no Ir.340, de 7 de agosto de 2006. Brasília, DF: Presidência da República, 2006. Disponível em: http://www.planalto.gov.br/ccivil_03/_ato2004-2006/2006/lei/li1340.htm. Acesso em: 04 Jul. 2021.

BRASIL. Lei no 13.718, de 24 de setembro de 2018. Brasília, DF: Presidência da República, 2018. Disponível em: http://www.planalto.gov.br/ccivil_03/_ato2015-2018/2018/lei/Lr3718.htm. Acesso em: 04 Jul. 2021.

BRASIL. Lei no 12.015, de 7 de agosto de 2009. Brasília, DF: Presidência da República, 2009. Disponível em: http://www.planalto.gov.br/ccivil_03/_ato2007-2010/2009/lei/li2015.htm. Acesso em: 04 Jul. 202I.

BRASIL. Lei no 8.072, de 25 de julho de 1990. Brasília, DF: Presidência da República, 1990. Disponível em: http://www.planalto.gov.br/ccivil_03/leis/18072.htm. Acesso em: 04 Jul. 202I.

BRITO, J. C. de S.; EUlÁliO, Maria do C.; DA Silva JúNiOR, E. G. A Presença de Transtorno Mental Comum em Mulheres em Situação de Violência Doméstica. Contextos Clínicos, v. 13, n. I, p. 198-220, 2020.

BUTLER, J. Quadros de guerra: quando a vida é passível de luto? Trad. Sérgio Tadeu de Niemeyer Lamarão e Arnaldo Marques da Cunha. Rio de Janeiro: Civilização Brasileira. 2016.

FREIRE, P. Pedagogia do oprimido. São Paulo: Paz e Terra, 2019.

GLOBO. Três crianças ou adolescentes são abusadas sexualmente no Brasil a cada hora. Por Thiago Herdy, 2020. Disponível em: https://oglobo.globo.com/sociedade/tres-criancas-ouadolescentes-sao-abusadas-sexualmente-no-brasil-cada-hora-24280326. Acesso em: 04 Jul. 2021. 
LABIAK, F. P.; MIGUEL, A. M.; NUNES, A. C. Educação emancipatória no curso de Direito: desafios e potencialidades. In: MAROCCO, A. de A. L.; PREVE, D. R.; PITSICA, H. N. P.; PILAU, N. C. (Org.). A Educação Jurídica no Brasil: perspectivas em debates. red. Santa Cruz do Sul: Essere Nel Mondo, 2021, v. I, p. 31-50.

LABIAK, F. P.; NOVAIS, M. M. DE; NUNES, A. C.; SILVA, M. O. da. A extensão universitária como protagonista de uma educação emancipatória: experiências do projeto de extensão Direito Intergeracional e Transversalidade da UNIVALI. Revista Diversidade e Educação, v. 8, p. 286-312, 2021.

LABIAK, F. P.; SAlES, S. S.; ARAÚJO, P. H. de M.; CRUZ, R. M.; LUZ, R. A. da. Feminicídio: um desfecho fatal para a desigualdade de gênero. In: ALMEIDA, F. A. de. (Org.). Desigualdade Social e de Gênero: desafios, perspectivas, retrocessos e avanços. red. São Paulo: Científica Digital, 2021, v. I, p. II4-I36.

LABIAK, F. P.; MIGUEL, A. M. (Trans)bordar a cultura do respeito à diversidade: pessoas transgêneras e os contextos educacionais e de trabalho. Empório do Direito, v. I, 2020.

MACHADO, H. B.; LUENEBERG, C.F.; RÉGIS, E. I.; NUNES, M. P. P. Abuso sexual: diagnostico de casos notificados no município de Itajaí/SC, no período de 1999 a 2003, como instrumento para a intervenção com famílias que vivenciaram situações de violência. Texto Contexto Enferm., I4, 2005, p. 54-63.

MIGUEL, A. M.; LABIAK, F. P. Ser transgênero e estar custodiado em instituições de privação de liberdade em instituições de privação de liberdade durante a pandemia da Covid19. In: NOGUEIRA NETO, J. M. (Org.). Saúde, sabedoria populares e os múltiplos contextos em tempos de crises. red. Sobral: Faculdade Luciano Feijão, 2021, v. 6, p. 193-226.

MIGUEL, A. M.; LABIAK, F. P. O que fazer quando a ameaça da saúde psíquica é (in)visível: enfrentamento e implicações da COVID-I9. Âmbito jurídico, v. I97, p. I-I, 2020a.

MIGUEL, A. M.; LABIAK, F. P. Tipificação do dano psíquico resultante da violência psicológica como crime de lesão corporal: Entraves dos mecanismos opressores da sociedade contemporânea. Âmbito jurídico, v. XXXIII, p. I, 20206.

MUNIZ, F. M. Estupro como arma de guerra: Estudo sobre a guerra da ex-lugoslávia. In: BAGGENSTOSS, G. A.; SANTOS, P. R. dos; SOMMARIVA, S. S.; HUGLL, M.de S. (Org.). Não há Lugar seguro: Estudos e práticas sobre violências contra as mulheres nas perspectivas dos direitos sexuais e reprodutivos. Poder Judiciário/Tribunal de Justiça de Santa Catarina e Universidade Federal de Santa Catarina. Florianópolis. Vol. 4, 2019.

ONU MULHERES. ONU alerta para os custos da violência contra as mulheres no mundo. Brasil. 2017. Disponível em: http://www.onumulheres.org.br/noticias/onu-alerta- para-oscustos-da-violencia-contra-as-mulheres-no-mundo/ Acesso em: II Set. 2021. 


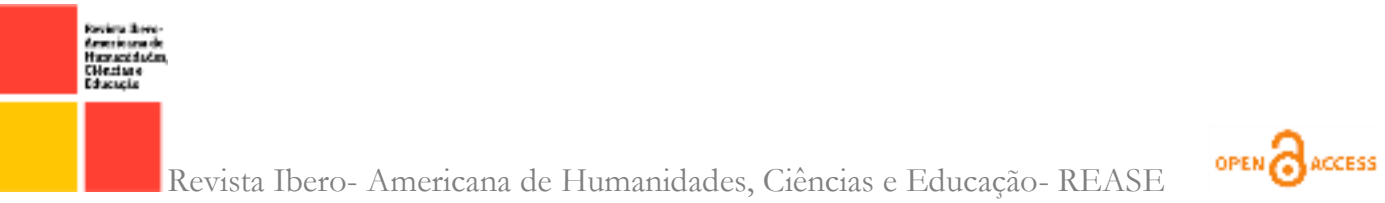

RIBEIRO, D. É preciso discutir por que a mulher negra é a maior vítima de estupro no Brasil. El País, São Paulo, 2016. Disponível em: https://brasil.el.pais.com/brasil/2or6.politica/.html. Acesso em: $04 \mathrm{Jul}$ 202I.

SECRETARIA DE SEGURANÇA PÚBLICA DO ESTADO DE SANTA [SSP/SC]. Ocorrências de violências e crimes contra as mulheres 2014 a 2020. Ouvidoria SSP. Disponível em: http://www.ouvidoria.sc.gov.br/cidadao

SECRETARIA NACIONAL DE SEGURANÇA PÚBLICA DO MINISTÉRIO DA JUSTIÇA [SNSP/MJ]. Pesquisa Nacional de Vitimização. Parceria Datafolha/Crisp/SENASP, 2013. Disponível em: https://www.crisp.ufmg.br/wpcontent/uploads/2013/ro/Relat\%C3\%B3rio-PNV-Senasp_final.pdf. Acesso em: 04 Jul 202I.

SEGATO, R. L. La guerra contra las mujeres. I ed. Madrid: Traficantes de Sueños, 2016. 